\title{
Erratum to: Decreased pyramidal neuron size in Brodmann areas 44 and 45 in patients with autism
}

\author{
Sarah Jacot-Descombes • Neha Uppal • Bridget Wicinski • \\ Micaela Santos • James Schmeidler • Panteleimon Giannakopoulos • \\ Helmut Heinsen - Christoph Schmitz • Patrick R. Hof
}

Published online: 24 April 2012

(C) Springer-Verlag 2012

\section{Erratum to: Acta Neuropathol \\ DOI 10.1007/s00401-012-0976-6}

In the author list of this article, the last name of the seventh author was erroneously spelled "Heinsein" and should have read "Heinsen".

The online version of the original article can be found under doi:10.1007/s00401-012-0976-6.

S. Jacot-Descombes - N. Uppal - B. Wicinski - M. Santos · P. R. Hof $(\bowtie)$

Fishberg Department of Neuroscience, Mount Sinai School of Medicine, One Gustave L. Levy Place, Box 1065,

New York, NY 10029, USA

e-mail: patrick.hof@mssm.edu

J. Schmeidler

Department of Psychiatry, Mount Sinai School of Medicine,

New York, NY 10029, USA

N. Uppal

Seaver Autism Center, Mount Sinai School of Medicine,

New York, NY 10029, USA

S. Jacot-Descombes · M. Santos · P. Giannakopoulos Department of Mental Health and Psychiatry, University

Hospitals and School of Medicine, Geneva, Switzerland
P. Giannakopoulos

Department of Psychiatry, University of Lausanne School

of Medicine, Lausanne, Switzerland

H. Heinsen

Morphological Brain Research Unit, Department of Psychiatry, Psychosomatics, and Psychotherapy, University of Wuerzburg,

Wuerzburg, Germany

C. Schmitz

Department of Neuroanatomy, School of Medicine,

Ludwig-Maximilians University, Munich, Germany 